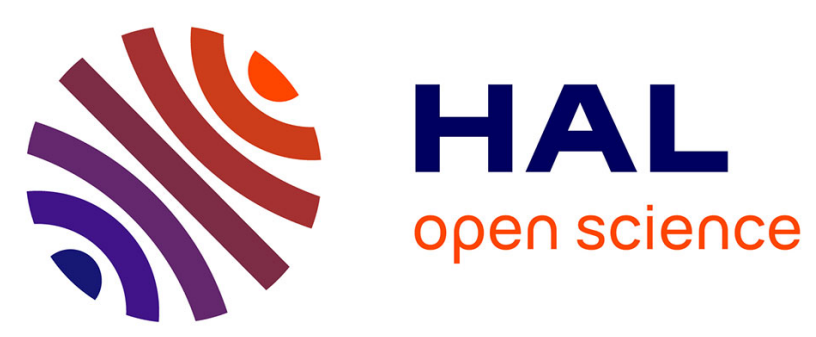

\title{
Prognosis of outcome in adult survivors of road accidents in France: 1-year follow-up in the ESPARR cohort
}

Hoang-Thy Nhac-Vu, Martine Hours, Laetitia Chossegros, Pierrette Charnay, Hélène Tardy, Jean-Louis Martin, Jean-Michel Mazaux, Bernard Laumon

\section{- To cite this version:}

Hoang-Thy Nhac-Vu, Martine Hours, Laetitia Chossegros, Pierrette Charnay, Hélène Tardy, et al.. Prognosis of outcome in adult survivors of road accidents in France: 1-year follow-up in the ESPARR cohort. Traffic Injury Prevention, 2013, 40p. 10.1080/15389588.2013.804180 . hal-00866403

\section{HAL Id: hal-00866403 https://hal.science/hal-00866403}

Submitted on 26 Sep 2013

HAL is a multi-disciplinary open access archive for the deposit and dissemination of scientific research documents, whether they are published or not. The documents may come from teaching and research institutions in France or abroad, or from public or private research centers.
L'archive ouverte pluridisciplinaire HAL, est destinée au dépôt et à la diffusion de documents scientifiques de niveau recherche, publiés ou non, émanant des établissements d'enseignement et de recherche français ou étrangers, des laboratoires publics ou privés. 
Prognosis of outcome in adult survivors of road accidents in France: 1-year follow-up in the ESPARR cohort

\section{TRAFFIC INJURY PREVENTION}

Hoang-Thy NHAC-VU ${ }_{a}$, Martine HOURS $_{a}$, Laetitia CHOSSEGROS $a$, Pierrette CHARNAY , Hélène TARDY $_{a}$, Jean-Louis MARTIN ${ }_{a}$, Jean-Michel MAZAUX ${ }_{b}$, Bernard LAUMON

a Université de Lyon, F-69622, Lyon, France ;

Université Lyon 1, UMRESTTE, F-69373 Lyon ;

IFSTTAR, UMRESTTE, F-69675 Bron.

vu.hoang-thy-nhac@ifsttar.fr;

martine.hours@ifsttar.fr;

laetitia.chossegros@ifsttar.fr;

pierrette.charnay@ifsttar.fr;

helene.tardy@ifsttar.fr;

jean-louis.martin@ifsttar.fr;

bernard.laumon@ifsttar.fr;

${ }^{\mathrm{b}}$ Rehabilitation and Physical Medicine Unit, Clinical Neuroscience Pole - Bordeaux University, SaintAndré and Pellegrin Hospitals, Bordeaux, France

jean-michel.mazaux@chu-bordeaux.fr; 
ABSTRACT (385 words)

\section{Objective}

The consequences of road crashes are various, and few studies have dealt with the multidimensionality of outcomes. The aim of the present study was to assess the multidimensional nature of outcomes one year after a crash and to determine predictive factors which could help in adapting medical and social care to prevent such consequences to improve road-crash victims' prognosis.

\section{Methods}

The study population was the 886 respondents to the one year follow-up from the ESPARR cohort, aged $\geq 16$ years; the analysis was carried out only on the 616 subjects who fully completed a selfreport questionnaire on health, social, emotional and financial status 1 year after a crash. Multiple correspondence analysis and hierarchical clustering was implemented to produce homogeneous groups according to differences in outcome. Groups were compared using the WHOQol-Bref (a standard instrument of quality of life, assessing physical health, psychological health, social relationships and environment) and the IIS (Injury Impairment Scale), a tool to predict road-crash sequelae.

Baseline predictive factors for group attribution were analyzed by weighted multinomial logistic regression models.

\section{Results}

370 of the 616 subjects (60.1\%) were men. Mean age was 36.9 years (standard deviation=16.5).

Five victim groups were identified in terms of consequences at 1 year: one group (206 subjects, 33.4\%) with few problems, one with essentially physical sequelae, one with problems that were essentially both physical and social, and two groups with a wider range of problems (one including psychological problems but fewer environmental problems, and the last one reported negative physical, psychological, social and environmental impact; notably, all had PCS).

There were significant differences between groups in terms of family status, injury severity and certain types of injury (thorax, spine, lower limbs).

Comparison on the WHOQol-Bref confirmed that groups reporting more adverse outcomes had a lower quality of life. Description of the 5 groups by IIS indicators showed that IIS underestimated physical consequences 1 year after the crash. 
Beside the known prognostic factors such as age, initial injury severity and lesion type, socioeconomic fragility and having a relative involved in the accident emerged as predictive of poor outcome at one year.

\section{Conclusions}

One year after the crash, victims may still be experiencing multiple problems in terms not only of physical health but also of mental health, social life and environment. Poor outcome may be predicted from both accident-related factors and socioeconomic fragility. Our results are useful in catching the attention of both clinicians and the public administration regarding victims at risk of suffering from important consequences after an accident. If those suffering head injuries are recognized, it would be very important to better consider and treat PTSD or PCS. Furthermore, subjects from lower socioeconomic backgrounds, with or without lower limb lesions have numerous difficulties after an accident, notably for returning to work: an objective would be to provide them more specific support.

\section{Keywords}

Outcome prediction, road-crash, homogeneous outcome groups, Injury Impairment Scale, WHOQolBref, ESPARR. 


\section{INTRODUCTION}

Road crashes can have long-term impacts on victims' lives, such as functional impairment (Holtslag et al. 2007), restricted daily activity and social life (Mayou et al. 2001), psychological problems (Holbrook et al. 2004) and financial problems (Barnes et al. 2006). Understanding these outcomes would be useful for improving healthcare quality by applying the most appropriate strategies. In addition, knowledge of predictive factors for outcome could help in adapting medical and social care so as actively to prevent such consequences.

The consequences of road accidents are various, and few studies have dealt with the multidimensionality of outcomes. Moreover, while victims with serious consequences can obviously be expected to have a relatively impaired quality of life (Holbrook et al. 2004, Barnes et al. 2006), this impairment may, according to the victims, involve several factors, related not only to the accident but often to intercurrent events.

In the field of road accident research, the Injury Impairment Scale (IIS) is an indicator derived from the Abbreviated Injury Scale (AIS) (AAAM 1990), predicting 1-year post-trauma impairment related to each specific lesion. In the absence of follow-up information, the IIS was used to assess trauma outcome in several studies (Amoros et al. 2008, Barnes et al. 2009). Some studies compared predicted and observed outcome (Barnes et al. 2009, Spicer et al. 2011, Nhac-Vu et al. 2012), and found no exact coherence between the outcome predicted by the IIS and the real outcome. A sequela prediction tool, however, would be useful for setting up preventive strategies.

Previous reports showed that victims suffering the most severe injuries at the time of the crash more frequently had poor physical outcomes at 1 year (Mayou et al. 2002a), deteriorated physical health at 6 months (Harris et al. 2008), disabling illness and psychological distress (Li et al. 2001), psychological trauma at 1 year (Jeavons 2000), or post-traumatic stress syndrome (PTSD) at 1 year (Koren et al. 2002).

Concerning the impact of age on outcome, our team previously reported that the risk of pain at 6 months was lower in young victims (Hours et al. 2010); Cunningham (Cunningham et al. 2001) confirmed the strong correlation between age and persistent occupational and/or functional disability; and Harris (Harris et al. 2008) showed that increasing age was associated with poorer physical and mental health. 
Concerning the impact of gender on outcome, Jeavons (Jeavons et al. 2000) reported that women had significantly more distress at 6 months and were at higher risk of impaired quality of life and of PTSD at 18 months; Mayou (Mayou et al. 2002b) found that women were more likely to report pain at 1 year.

Concerning the impact of socio-environmental status, previous studies showed that subjects with a favorable occupation (Cornes 1992), better income (Harris et al. 2008) or higher educational level or who were in work (Ottosson et al. 2005) reported better recovery.

The results of the present study showed that a given factor could be predictive of different outcomes and that a given outcome could be associated with different risk factors. Consequences are thus obviously interlinked, and an analysis taking them all into account should give a more comprehensive picture of outcome. Moreover, adjusting predictive factors on each other enables a maximum amount of information to be taken into account and analyzes their respective impacts more precisely, without bias induced by interaction.

Therefore the aim of the present study was to assess the multidimensional nature of outcomes 1 year after the crash and to determine predictive factors which could help in adapting medical and social care so as to improve road-crash victims' prognosis. The study was founded on the ESPARR cohort data-set (Étude et Suivi d'une Population d'Accidentés de la Route dans le Rhône: follow-up study of road-accident victims in the Rhône administrative département of France) based on 1-year follow-up.

\section{METHODS}

\section{Subjects}

The study was based on the ESPARR cohort (Hours et al. 2010), which is a prospective study of road-crash victims in the Rhône administrative département of France. From October 2004 to July 2006, 1,372 victims were recruited to the cohort. Lesions were coded on the AIS, which attributes lesion severity grades from 1 (minor) to 6 (fatal). Immediate prognosis was assessed on the M-AIS (the AIS score for the victim's most severe lesion). Given the strong skew between mild and severe injury, differential sampling fractions were implemented according to initial lesion severity, recruiting all victims with severe injury (M-AIS $\geq 3$ ) and 1 in 6 of those with slight or moderate injury (M-AIS $<3)$. Cohort inclusion criteria were: 1- having had a road accident in the Rhône administrative département (France) involving any vehicle; 2 - living in the Rhône département; 3- having been admitted to one of 
the hospitals in the département; and 4- having survived the crash at least up to hospital admission. The ESPARR cohort is, moreover, a subpopulation of the Rhone Registry of road accident victims, which has been collecting almost exhaustive data on road accidents involving injury in the area since 1995 (Laumon et al. 1997). Initial interviews are performed when the victim reaches hospital, and these data are supplemented by the initial injury report based on the hospital data. A follow-up of the cohort was conducted to assess the physical, mental and social/environmental consequences of the crashes on the victims and their families at 1,2, 3 and 5 years.

The present study included only participants aged 16 years or over who gave (or whose parents gave) informed consent to the study: i.e., 1,168 subjects. 886 (76\%) of them responded to the followup 1 year later. Due to missing data, only the 616 participants who completed all the items of the questionnaire were included in the final analysis (Figure 1).

The representativeness of the population used in this analysis of predictive factors was compared, by a weighted chi ${ }^{2}$ test, to the population of $\geq 16$ year-old cohort members failing to answer in full or only in part to the 1-year questionnaire.

\section{Definition Of Variables And Scores}

Personal data: Victim characteristics were described by age, gender, familial status and socioeconomic fragility. In order to synthesize all the available socioeconomic information in the study population, a single variable of socioeconomic fragility (6 levels) was derived from the following information: socio-occupational category (White-collar worker; Intermediate-level employee; Farmer, craftsman or shopkeeper; Blue-collar worker; Student or housewife); familial status (Single parent; Family; Single); occupational stability (Not working, stable; Not working, not stable; Working, stable; Working, not stable [not stable $=$ job-seeker, or under private-sector short-term contract, or independent professional, or short-term public sector contract, intern/sandwich-course or apprenticeship]); educational level (< school-leaving certificate; school-leaving certificate; > schoolleaving certificate); living in a disadvantaged area versus not; home-owner versus tenant; living in a house versus not; negative affective event (children leaving home, divorce or separation or break-up, or death of relative or friend); negative social event (job loss, money problems or business failure); previous hospital admission; presence of pre-accident pathology (heart problem, asthma or diabetes, 
etc.), having complementary health insurance versus not; practicing an artistic/craft activity versus not; practicing a sport versus not.

Accident-related data: Type of road user; self-reported degree of responsibility for the accident (in case of missing information, some degree of responsibility was systematically attributed; when the victim was the only driver involved, he or she was considered responsible; passengers, cyclists and pedestrians were considered non-responsible).

Injury pattern: Lesions were categorized as present/absent according to 8 injury types: head, face, whiplash, thorax, abdomen, spine without whiplash, upper limbs, and lower-limbs. Severity was described by the New Injury Severity Score (NISS) (Osler et al. 1997), equaling the sum of the squares of the AIS severity scores for the 3 most severe lesions, enabling multiple trauma to be taken into account.

Prediction tools: The Injury Impairment Scale (IIS) is an international index which, associated to lesion description, predicts 1-year sequelae, taking into account mobility, cognitive, esthetic, sensory and sexual/reproductive aspects and pain. Like the AIS, the IIS has 6 levels of severity (plus a level-0 for lesions without foreseeable sequelae):

$0=$ Normal function, no impairment.

$1=$ Detectable impairment without limitation of normal functions.

$2=$ Impairment compatible with most but not all normal functions.

$3=$ Impairment compatible with only some usual functions.

4 = Impairment significantly impairing some normal functions.

$5=$ Impairment preventing most essential functions.

$6=$ Impairment preventing all essential functions.

For each victim, the IIS information was summarized in three ways: MIIS (maximum IIS predicted for the subject); NLesionIIS (number of lesions with IIS> 0); and NRegionlIS (number of body regions with at least one IIS>0 lesion).

Outcome measurements at one year: The 13 outcome variables selected for analysis, representing physical health, psychological health, and socio-environmental status, are detailed in Table A1.

Quality of life at one year: Quality of life was evaluated on a standard instrument (the WHOQolBref), which contains 26 items: 2 global quality-of-life items assessing overall satisfaction with life and general sense of personal well-being, and 24 other items covering 4 domains: physical health (7 
items), psychological health (6 items), social relationships (3 items), and environment (8 items). Responses to each item were coded from 1 to 5, summed, and transformed into a scale from 0 (worst health-related quality of life) to 100 (best health-related quality of life) (WHO 1998).

\section{Statistical Analysis}

Step 1: Homogeneous consequence groups: a data mining process was implemented to try to capture the multidimensionality of 1-year outcomes.

- A multiple correspondence analysis (MCA) was performed with the 13 variables concerning consequences at 1 year, covering 4 domains (physical health, mental health, social life, and environment).

- Cluster analysis (Hierarchical Ascendant Classification) was used to classify the victims into homogeneous outcome groups, using all the factorial axes obtained by the MCA. Clustering began with each individual counting as a "group" in itself; pairs of most similar groups were then progressively clustered together, constructing the hierarchy. The choice of which groups to merge or split was determined by Ward's minimum-variance method (Ward 1963), in which the distance between two groups is the variance sum of squares between the two groups summed over all axes. The numbers of groups in the cluster analysis was determined on a dendrogram; the cubic clustering criterion (CCC) was then used to evaluate clustering quality, with $\mathrm{CCC}>2$ indicating good clusters.

\section{Step 2: Description of each group}

Each group was described in terms of sociodemographic and lesion variables, using the WHOQolBref (2 global questions, and 4 scores) and IIS indicators. Groups were compared by a weighted chi test (Rao-Scott), taking account of the sampling strategy so as to enable comparison. Weighting was based on injury severity in the study population proportional to the corresponding data for the total population of road-accident victims (surviving the accident and aged $\geq 16$ years) in the same geographical area (Rhône département) over the same period (October 2004 to July 2006) (data available from the Rhône Road-Accident Registry). The scores of the 5 groups in the 4 WHOQol-Bref domains (physical health, psychological health, social relationships and environment) were compared by the non-parametric Kruskal-Wallis test. The statistical significance threshold was set at $p<0.05$.

Step 3: Factors associated with 1-year outcome 
Outcome prediction factors were analyzed using weighted multinomial logistic regression models, taking the sampling design into account. The variable to be explained (non-ordinal variable in 5 modalities) attributed each modality to one of the homogeneous 1-year consequence groups, as defined above. The explanatory variables comprised demographic factors (age and gender), accidentrelated factors (responsibility in the accident, having a relative involved in the accident, severity and type of lesion), and socioeconomic fragility status.

Variables significantly related to outcome in univariate analysis were included in the multivariate model, with attention paid to collinearity. Age and gender were used as adjustment variables, and then included regardless of their significance level. The variables most significantly associated with outcome ( $5 \%$ threshold) were adjusted one by one on an ascending stepwise procedure. First-order interactions were tested between the explanatory variables of the final model.

Statistical analysis used the SurveyFreq and SurveyLogistic procedures of the SAS ${ }$ software package, version 9.3 .

\section{RESULTS}

\section{Description Of The Study Population}

The mean age of the 616 respondents was 36.9 years (standard deviation, SD=16.5). Nearly twothirds $(n=370,60.1 \%)$ were men; more than half had mild or moderate injury (NISS [0 - 8], $n=321$; $52.1 \%)$.

The comparison of the population involved in this predictive factor analysis $(n=616)$ and those of the $\geq 16$ year-old ESPARR cohort subjects who did not answer all items on the 1-year questionnaire ( $n=552)$ shows no difference in occupational status at the time of the accident, pre-accident pathology, having a relative involved in the accident or having injuries other than a head injury; nonrespondents, however, were slightly younger, more often male (64\% vs 60\%), with a greater socioeconomic fragility (socially exposed : $20 \%$ vs $12 \%$ ) and were less seriously injured (NISS $<9$ : $79 \%$ vs $52 \%)$.

Of the 13 outcome variables of the cluster analysis, poor subjective health was the most frequently reported (72\%), followed by persistent sequelae at 1 year (66\%). Half of the population reported that the crash had disrupted recreational activities. However, 52 of the 444 victims reporting poor 
subjective health also declared no health problems such as persistent sequelae, medical treatment, increased psychiatric treatment, post-traumatic stress or post-concussion syndrome (PCS).

\section{Consequence Groups}

The dendrogram obtained from the MCA suggested 5 or fewer clusters. CCC was greater than 2 $(\mathrm{CCC}=4.5)$ for 5 or more clusters. Combining these 2 criteria, a 5 -cluster design appeared the most appropriate.

As shown in Table A2, 5 consequence groups were distinguished:

- Group 1: $33.4 \%$ of the population $(n=206)$. Most subjects in this group reported good health recovery, without negative psychological impact, only a few experiencing any negative social or environmental impact.

- Group 2: $27.7 \%(n=168)$. Most subjects in this group reported physical health issues, but with little psychological, social or environmental impact.

- Group 3: $25.8 \%(n=159)$. This group was characterized by poor general health status, associated with some negative social and environmental impact, but with few cases of negative psychological impact.

- Group 4: $7.0 \%(n=43)$. This group reported poor general health status, associated with negative social and environmental impact, with almost half of the subjects also reporting psychological problems: $34.9 \%$ post-traumatic stress and $41.9 \%$ intensified psychiatric treatment during the year following the accident. None of the victims in this group had fully recovered health status, and all had changed residence for accident-related reasons.

- Group 5: 6.5\% ( $n=40)$. Most subjects in this group reported negative physical, psychological, social and environmental impact; notably, all had PCS.

\section{Group Comparison By Sociodemographic And Lesion Characteristics At Inclusion}

As shown in Table 1, there were significant differences between the groups in terms of family status, socioeconomic fragility, having a relative involved in the accident, severity of injury and certain types of lesion (thorax, spine, lower-limbs).

Studying the group characteristics in more detail, group 1 was found to include a very large proportion of mild injuries. Group 2 mainly involved mild injury, although less than in group 1. Groups 1, 2 and 3 had higher rates of whiplash injury than groups 4 and 5 . Half of the group 3 subjects had had a 
motorcycle accident, and two-thirds had lower-limb injuries. Group 4 had a high rate of lower-limb involvement, and had the highest proportions of males and of severe injury (NISS $\geq 9$ ). Group 5 had the highest rate of psychological and social consequences and also the highest proportion of single persons (60\%); there were elevated rates of severe injury, including systematic head involvement, with half of the subjects reporting facial injury, and also a higher rate of 4-wheel vehicle users than in the other groups.

\section{Group Comparison By WHOQol-Bref}

$61.9 \%$ of the whole population rated their quality of life as good or very good, and $50.7 \%$ were satisfied or very satisfied with their health status (Table 2). A significant difference was found between groups concerning satisfaction with life and general sense of personal well-being $(p<0.01)$ : groups 1 and 2 reported good quality of life $(>67.0 \%)$ or were satisfied with their health, which was not the case for the other 3 groups.

The 5 groups differed in the 4 WHOQol-Bref domains (Figure 2). Kruskal Wallis 1-way analysis of variance (results not presented in the Table 2, as all were significant: $p<0.01$ ) found good correlation between quality of life on the $4 \mathrm{WHOQ}$ ol-Bref scores and outcomes in the various groups: groups with lower WHOQol-Bref scores (lower quality of life) reported more adverse outcomes than those with higher scores. For example, Group 1, which had the fewest consequences on the majority of the outcome measurements, had the best scores in all WHOQol-Bref domains, while Group 4, which had the most environmental consequences, had the worst scores in the environmental domain.

\section{Group Comparison By IIS Indicators}

Comparing the 5 groups by IIS, different IIS indicators were tested for relevance to the outcome groups. The 5 groups differed in terms of IIS, whichever the indicator used (Table A3):

- In terms of maximum predicted sequelae (MIIS), the proportion of victims with impairment compatible with most but not all normal functions (MIIS $\geq 2$ ) in each group increased steadily from group 1 to group 5 (6.8\%; 9.0\%; 12.6\%; 37.5\%; 39.6\%, respectively). In terms of the number of lesions with sequelae in each group (NLesionIIS), the proportion of victims having at least 2 lesions with sequelae increased from group 1 to group 3 and then decreased from group 4 to 
group 5. Comparing the 5 groups by the number of regions with sequelae (NRegionIIS), the proportion of subjects with at least 2 regions showing sequelae increased from group 1 to group 4.

- Comparison of MIIS per lesion type in the 5 groups could not be carried out, as the number of subjects with notable sequelae in most of the lesion types was zero. There was a very small number of victims with notable sequelae for certain lesion types: the proportion of victims with notable sequelae (MIIS>0) in the face, abdomen and thorax lesion was $1.8 \%, 0.4 \%$ and $2.8 \%$, respectively; neck lesions induced no notable sequelae. Consequently, most of the results are not presented in the Table A3. The 5 groups could, however, be distinguished in terms of head and lower-limb lesion sequelae: as shown above, in group 4 two-thirds of victims had at least 1 IIS $>0$ for the head; groups 3 and 5 showed higher sequelae rates, in terms of IIS, for the lower limbs. Seven of the 13 victims with spine sequelae were in group 4 with the highest rate of environmental consequences. It was also found that group 5, which included victims with multiple outcomes had the greatest number of facial sequelae.

\section{Risk Factors For Poor 1-Year Outcome}

Age, socioeconomic fragility status, having a relative involved in the accident, initial lesion severity and spinal or lower-limb lesions emerged as risk factors for poor outcome at 1 year (Table 3). Comparing each group to the reference group (group 1) showed an increasing correlation [OR (NISS $\geq 9$ vs NISS 0-8) increasing from 2.8 to 10.4 ] between severity (NISS $\geq 9$ ) and group rank (from group 2 to group 5).

Victims with spinal or lower-limb lesions were more likely to fall into group 3 (with mainly physical, social and environmental problems) than group 1 [OR $(95 \% \mathrm{Cl})=4.3(1.8-10.6)$ and $2.4(1.3-4.4)$, respectively].

After adjustment for injury severity, subjects with a relative also involved in the accident were at greater risk of falling into group 5 (poorest physical, psychological and social outcomes) [5.7 (1.917.0)].

Subjects aged over 24 years were at greater risk of falling in group 4 than those aged 16-24 years.

Subjects classified D, E or F for socioeconomic fragility were at greater risk of falling into group 4 [OR $(95 \% \mathrm{Cl})$ respectively $11.6(1.2-109.9), 5.4(1.2-24.3)$ and 35.8 (7.1-181.5)], although sample sizes were small. 


\section{DISCUSSION}

Multidimensionality of outcomes has been studied very little in road-accident victims, due to its complexity; and underlying factors have been studied even less. The present study assessed the relations between consequences at 1 year post-accident, and predictive factors for poor outcome at 1 year.

Five homogeneous groups of consequences were identified: group 1, showing good recovery, served as a reference; groups 2 and 3 comprised subjects with intermediate degrees of negative impact, related largely to physical deficits and difficulties (group 2), and to physical and social problems (group 3); groups 4 and 5 were both composed of subjects experiencing multiple concomitant problems but could be distinguished, with higher rates of environmental problems in group 4 and of psychological problems in group 5. Each of the 4 mean WHOQol-Bref scores lay in the upper half of the $0-100$ scale in the present study, indicating generally quite favorable quality of life levels 1 year after a crash. Comparison of the 5 groups by the WHOQol-Bref global score confirmed that each group was homogeneous and distinct from the others regarding quality of life. All 4 WHOQol-Bref domain scores decreased from group 1 to group 3, confirming increasing severity outcomes. The failure to find any trend across the 5 groups in terms of number of lesions or of regions with sequelae or in terms of body area with the maximal sequelae predicted by IIS can be explained by the fact that each group was constructed with consequences affecting several domains, whereas the IIS is related to only 1 domain.

In group 2, the IIS underestimated physical consequences at 1 year. Although the majority of group 2 had mainly physical consequences without other types of consequence, more than one-third were impairment-free at 1 year (34.5\% MIIS=0).

Concerning risk factors for poor 1-year outcome, after adjustment for several baseline variables assessed at the time of the accident, not only the well-known factors of age and gender but also socioeconomic fragility and the fact of having a relative involved in the accident emerged as predictive of long-term outcome. The results showed a clear difference in frequency of psychological problems between the 5 groups: PTSD was identified in $75.0 \%$ of group 5, 34.9\% of group 4 and $28.3 \%$ of group 3; few subjects in groups 1 and 2 reported PTSD. In research on objective health assessment, PTSD is one of the most frequently investigated psychological problems. The rate of PTSD in the present study (19\%) was similar to that reported by Mayou (Mayou et al. 2001) and lower than in 
Koren's study (32\%) (Koren et al. 1999). PCS was reported only in group 5. Regarding other outcomes in these groups, victims who suffered PCS also had PTSD, physical and social problems.

In agreement with previous reports (Harris et al. 2008, Hours et al. 2010), older subjects were found to be at greater risk of experiencing multiple problems at 1 year.

Occupation stability, educational level and socioeconomic status were mirrored in the present study as socioeconomic fragility status, under which various types of complementary information were combined. There seemed to be a trend toward elevated risk of poor recovery at 1 year associated with greater socioeconomic fragility at the time of the accident, but sample sizes were too small to be conclusive, with several high odds ratios failing to achieve significance.

Initial lesion severity has an obvious impact on adversity of outcome, and most of the victims in groups 4 and 5 had been severely injured in their accident. This finding is in line with previous reports (Mayou et al. 2002a, Harris et al. 2008, Hours et al. 2010) which found that the risk of falling into a group of more serious consequences increased with injury severity. In particular, the fact that none of the group-4 victims had recovered health status and that all had changed residence for accident-related reasons was related to injury severity; this was the group with the highest proportion of very severe injuries. Likewise, injury type was related to consequences at 1 year: in groups 3 and 4, more than two-thirds of the subjects had lower-limb involvement, and restricted leisure activity was notably frequent ( $88.7 \%$ and $95.3 \%$, respectively); PCS was also a feature of group 5, where $100 \%$ of the victims had had head injuries, which were therefore not introduced in the final model; this is an important fact, showing the particularly unfavorable outcome experienced after such injury. Head lesions were notably associated with PCS.

Type of road user was reported in the literature as a predictive factor for consequences, the types most at risk of poor outcome being 2-wheel drivers (Jeavons et al. 2000) and pedestrians (Mayou et al. 2003); however, this was not included in the present multivariate analysis, due to collinearities. It is a variable that is closely associated with certain kinds of lesion, such as whiplash, chest or lower-limb injury, and also with victim responsibility, injury severity and having a relative involved in the accident. Introducing several accident-related factors in the model and not the type of road user itself shed better light on how accident-related factors affect consequences. For example, having a relative injured in the accident influences outcome, but has been very little studied in the literature; it may induce psychological disorder related to an accumulation of 
disturbances in family life. In the present results, 4-wheel vehicle users were the most concerned by this factor. Spinal lesions, a dominant factor for 4-wheel vehicle users, and lower-limb lesions, a dominant factor for pedestrians and 2-wheel motor vehicle users, also emerged as predictive of poor outcome at 1 year.

The predictive value of gender is controversial: some studies reported higher rates of negative consequences in females (Barnes et al. 2006, Harris et al. 2008), others in males (Valent et al. 2002, Vorko-Jovic et al. 2006); no predictive value one way or the other emerged from the present results. In previous analyses (Hours et al. 2008, Chossegros et al. 2011), our team found that victims not considered responsible for their accident showed poorer recovery, suggesting that these subjects feel themselves to be helpless victims of misfortune; this was not borne out by the present results, nor by other studies (Mayou et al. 1993, Jeavons 2000).

The present study has several strong points:

Firstly, the influence of the victim's socioeconomic situation was assessed, which has rarely been the case in the literature, probably because of a lack of information. Previous studies (Gaulle-Anthonioz 1995, Lecomte et al. 1996) demonstrated socioeconomic fragility to be multifactorial and mainly expressed in the following domains: socioeconomic status, housing, occupational situation, educational level and health status. It is thus necessary to dispose of those kinds of information if this variable is to be studied; this was not always the case in previous reports, whereas the ESPARR data-set allowed exactly this. Moreover, using a multidimensional factor optimizes the use of the data. There are in fact correlations between the various factors involved in socioeconomic fragility: having experienced a negative event, living alone, having already had health problems prior to the accident, low educational level, low sociodemographic category, occupational instability, lack of complementary health insurance to supplement the basic national health insurance cover, residence in a disadvantaged urban area, etc. Combining these data provides full information while avoiding bias due to introducing the same information repeatedly.

Consequences of accidents are often looked at through the physical disability and its consequence on functional independence and through the mental perturbations caused by the accident. Usually, social, financial, familial consequences are not taken into account, so assessing several types of consequence provides a full picture of outcomes and permits a look for their impact on the daily 
quality of life. So for us, it was very interesting to take into account all these aspects by creating the typology of the groups of outcomes.

Furthermore we used the concept of quality of life which covers numerous domains of personal and affective life and also social and occupational relations such as the EuroQol (Barnes et al. 2006) or the WHOQol-Bref. The interest of the latter is that it gives a global evaluation and scores in four domains which are good summaries of all this information; using quality of life to validate the construction of our typology permits us to confirm its relevance.

If head lesions are known to generate a lot of difficulties after the accident, our results show, in particular, the impact of PCS troubles or PTSD on the future of such victims: this association between PCS or PTSD and head trauma (whatever the seriousness of the initial head lesion) has to be further explored through medical research to better understand these outcomes.

Another area to be explored in more detail is the consequences of lower limb lesions, whose (particularly physical) consequences are very significant at the one year follow-up and generate difficulties. The socioeconomic fragility has to be taken into account more often in studies about accidents. One of the possible developments will be to control if the consequence groupings remains strong over the years. It would be interesting to build a risk score from the predictive factors we have found, which could then be proposed to clinicians as a help to identify vulnerable patients (beyond the severity of the initial lesion), as soon as the first care after the accident is given.

However, some limitations remain:

Most measurements were self-reported, which may have biased the results, although several studies have demonstrated the quality of subjective assessment in predicting real health status (HudekKnezevic et al. 2009), particularly in populations with health problems (Arnold et al. 2005, Saevareid et al. 2007). While we had a rich data base for 1,168 adult subjects, a large proportion of them $(n=552$, or $47 \%)$ failed to respond to all items in the 1-year questionnaire. Non-respondents were younger, more often male and single, with greater socioeconomic fragility and less seriously injured. These factors were included in the multivariate model, which decreased the bias due to nonrespondents; despite all that, some bias could persist.

Predictive factor analysis was thus based on only 616 victims, which made for small sample sizes in some cases. Subjects were therefore sometimes grouped together to increase statistical power, as in the case of type of road user or of NISS. However, this was not done where it would have led to the 
loss of important information such as the various degrees of socioeconomic fragility or the different age groups.

Groups 4 and 5 were small, and an attempt was made to merge them in order to increase statistical power; statistical comparison, however, showed them to differ significantly on all consequence variables. Analysis therefore proceeded on the basis of 5 groups. Some results therefore have to be taken with caution, due to small sample size. Also, consequence groups could only be established for subjects who had answered all of the items on the questionnaire used for the multiple correspondence analysis, which could have introduced bias. This was checked by comparing statistics for those who responded to the totality of the questionnaire and those who did not. The comparison showed that the latter group had a better opinion of their health than the former. These differences, however, would be liable to influence results in various directions, so that the impact of response-rate on the final results was probably slight.

A third issue that could be raised was that the same population was used to establish the consequence groups and to analyze predictive factors, whereas ideally the former should have been a preliminary step performed on a subpopulation. It was, however, decided to use the whole population, so as to secure statistical power in establishing the different groups, and this choice was in fact borne out by the results, which were in agreement with those of the literature.

In conclusion, the present study showed that, at 1 year-post-accident, road-accident victims may suffer multiple problems involving physical and mental health, and social and environmental life. Five subgroups emerged, distinct in terms of the severity of their problems of physical health, mental health, and social/environmental status; the groups were furthermore consistent with their respective scores in the 4 WHOQol-Bref domains. Poor outcome can be predicted not only from accident-related factors but also from factors involved in socioeconomic fragility, although further studies will be needed to confirm this finding.

Our results are useful in catching the attention of both clinicians and the public administration regarding victims at risk of suffering from important consequences after an accident. If those suffering head injuries are recognized, it would be very important to better consider and treat PTSD or PCS. Furthermore, subjects from lower socioeconomic backgrounds, with or without lower limb lesions have numerous difficulties after an accident, notably for returning to work: an objective would be to provide 
them more specific support. A better knowledge of the consequences for the victims could help to provide a better compensation after the accident; furthermore, it would allow the understanding of the victim by those around him/her, family and medical staff, with a view of facilitating his or her social reintegration.

\section{ACKNOWLEDGMENTS}

We acknowledge funding from the French Ministry of Equipment, Transport, Housing, Tourism and Sea (Predit 3 Program, "New Knowledge in the Field of Road Safety": No SU0400066), from the National Agency for Research (Program Predit 4 "Safe, reliable and adapted transport" No. ANR-07TSFA-007-01) and from the French Ministry of Health (PHRC 2003 Program: PHRC-N03 and PHRC 2005: PHRC- N051).

The individual authors have no competing interests to declare.

The authors are grateful to the victims for their cooperation in data collection. The authors would like to thank all those who assisted in carrying out this study: Nadia Baguena, Jean Yves Bar, Amélie Boulanger, Elodie Paquelet, Stuart Nash and Véronique Sotton for collecting the data, and Irène Vergnes for organizing the databases; Anne-Marie Bigot, Nathalie Demangel and Geneviève Boissier for subject database management; Blandine Gadegbeku, Amina NDyae and the Association for the Rhône Road Trauma Registry (ARVAC) for their help in collecting and providing medical data; the Scientific Committee (Jean-Louis Martin, Daniel Floret, Etienne Javouhey, Jacques Gaucher, Jacques Luauté and Dominique Boisson); all the hospital staff who accepted the interviewers' presence and who referred victims; and the SAMU medical ambulance team who reported their daily emergency interventions, all the UMRESTTE team for advice and assistance. 


\section{REFERENCES}

Aaam, 1990. The abbreviated injury scale, 1990 revision. Des Plaines, II, 60018 USA, pp. 74.

Amoros, E, Martin, JL, Laumon, B. Estimation de la morbidité routière, france, 1996-2004. Bull Epidémiol Hebdo. 2008;19:157-160.

Arnold, R, Ranchor, AV, Koeter, GH, De Jongste, MJ, Sanderman, R. Consequences of chronic obstructive pulmonary disease and chronic heart failure: The relationship between objective and subjective health. Soc Sci Med. 2005;61(10):2144-54.

Barnes, J, Morris, A. A study of impairing injuries in real world crashes using the injury impairment scale (iis) and the predicted functional capacity index (pfci-ais). Annu Proc Assoc Adv Automot Med. 2009;53:195-205.

Barnes, J, Thomas, P. Quality of life outcomes in a hospitalized sample of road users involved in crashes. Annu Proc Assoc Adv Automot Med. 2006;50:253-68.

Chossegros, L, Hours, M, Charnay, P, Bernard, M, Fort, E, Boisson, D, Sancho, PO, Yao, SN, Laumon, B. Predictive factors of chronic post-traumatic stress disorder 6 months after a road traffic accident. Accid Anal Prev. 2011;43(1):471-7.

Cornes, P. Return to work of road accident victims claiming compensation for personal injury. Injury: International Journal of the Care of the Injured 1992;23(4):256-260.

Cunningham, C, Howard, D, Walsh, J, Coakley, D, O'neill, D. The effects of age on accident severity and outcome in irish road traffic accident patients. Ir Med J. 2001;94(6):169-71.

Gaulle-Anthonioz, GD. Évaluation des politiques publiques de lutte contre la grande pauvreté. Rapport au conseil économique et social français, autosaisine adoptée le 12/7/1995. Journal officiel 27/7/1995 (no brochure 4277). 1995.

Harris, IA, Young, JM, Jalaludin, BB, Solomon, MJ. The effect of compensation on general health in patients sustaining fractures in motor vehicle trauma. J Orthop Trauma. 2008;22(4):216-20.

Holbrook, TL, Hoyt, DB. The impact of major trauma: Quality-of-life outcomes are worse in women than in men, independent of mechanism and injury severity. J Trauma. 2004;56(2):284-90.

Holtslag, HR, Van Beeck, EF, Lindeman, E, Leenen, LP. Determinants of long-term functional consequences after major trauma. J Trauma. 2007;62(4):919-27.

Hours, M, Bernard, M, Charnay, P, Chossegros, L, Javouhey, E, Fort, E, Boisson, D, Sancho, P-O, Laumon, B. Functional outcome after road-crash injury: Description of the esparr victims cohort and 6-month followup results. Accid Anal Prev. 2010;42(2):412-421.

Hours, M, Fort, E, Charnay, P, Bernard, M, Martin, JL, Boisson, D, Sancho, PO, Laumon, B. Diseases, consumption of medicines and responsibility for a road crash: A case-control study. Accid Anal Prev. 2008;40(5):17891796.

Hudek-Knezevic, J, Kardum, I. Five-factor personality dimensions and 3 health-related personality constructs as predictors of health. Croat Med J. 2009;50(4):394-402.

Jeavons, S. Predicting who suffers psychological trauma in the first year after a road accident. Behav Res Ther. 2000;38(5):499-508.

Jeavons, S, Greenwood, KM, Horne, DJ. Accident cognitions and subsequent psychological trauma. J Trauma Stress. 2000;13(2):359-65.

Koren, D, Arnon, I, Klein, E. Acute stress response and posttraumatic stress disorder in traffic accident victims: A one-year prospective, follow-up study. Am J Psychiatry. 1999;156(3):367-73.

Koren, D, Arnon, I, Lavie, P, Klein, E. Sleep complaints as early predictors of posttraumatic stress disorder: A 1year prospective study of injured survivors of motor vehicle accidents. Am J Psychiatry. 2002;159(5):855857.

Laumon, B, Martin, JL, Collet, P, Chiron, M, Verney, MP, Ndiaye, A, Vergnes, I, Year. A french road accident trauma registry : First results. In: Proceedings of the 41st AAAM conference, Orlando, Florida, pp. 127-137.

Lecomte, T, Mizrahi, A, 1996. Précarité sociale cumul des risques sociaux et médicaments. Enquête sur la santé et les soins médicaux, france 1991-1992 (social precarity: Holding a plurality of social and medical risks).

Li, L, Roberts, I, Power, C. Physical and psychological effects of injury. Data from the 1958 british birth cohort study. Eur J Public Health. 2001;11(1):81-83. 
Mayou, R, Bryant, B. Outcome in consecutive emergency department attenders following a road traffic accident. Br. J. Psychiatry. 2001;179:528-534.

Mayou, R, Bryant, B. Outcome 3 years after a road traffic accident. Psychol Med. 2002a;32(4):671-5.

Mayou, R, Bryant, B. Psychiatry of whiplash neck injury. Br. J. Psychiatry. 2002b;180:441-448.

Mayou, R, Bryant, B. Consequences of road traffic accidents for different types of road user. Injury: International Journal of the Care of the Injured. 2003;34(3):197-202.

Mayou, R, Bryant, B, Duthie, R. Psychiatric consequences of road traffic accidents. Br. Med. J. 1993;307(6905):647-651.

Nhac-Vu, HT, Hours, M, Charnay, P, Chossegros, L, Boisson, D, Luaute, J, Laumon, B. Evaluation of the injury impairment scale, a tool to predict road crash sequelae, in a french cohort of road crash survivors. Traffic Inj Prev. 2012;13(3):239-248.

Osler, T, Baker, SP, Long, W. A modification of the injury severity score that both improves accuracy and simplifies scoring. J Trauma. 1997;43(6):922-5; discussion 925-6.

Ottosson, C, Nyren, O, Johansson, SE, Ponzer, S. Outcome after minor traffic accidents: A follow-up study of orthopedic patients in an inner-city area emergency room. J Trauma. 2005;58(3):553-60.

Saevareid, HI, Thygesen, E, Nygaard, HA, Lindstrom, TC. Does sense of coherence affect the relationship between self-rated health and health status in a sample of community-dwelling frail elderly people? Aging Ment Health. 2007;11(6):658-67.

Spicer, RS, Miller, TR, Hendrie, D, Blincoe, LJ. Quality-adjusted life years lost to road crash injury: Updating the injury impairment index. Annals of Advances in Automotive Medicine. 2011;55:365-77.

Valent, F, Schiava, F, Savonitto, C, Gallo, T, Brusaferro, S, Barbone, F. Risk factors for fatal road traffic accidents in udine, italy. Accid Anal Prev. 2002;34(1):71-84.

Vorko-Jovic, A, Kern, J, Z, B. Risk factors in urban traffic accidents. J Safety Res. 2006;37(1):93-98.

Ward, JH. Hierarchical grouping to optimize an objective function. J Amer Statistical Assoc. 1963;58(301):236244.

Weathers, FW, Litz, BT, Herman, DS, Huska, JA, Keane, TM, Year. The ptsd checklist : Reliability, validity and diagnostic utility. In: Proceedings of the Annual Meeting of the International Society for Traumatic Stress Studies, San Antonio.

Who, Icd-10.

Who. Development of the world health organization whoqol-bref quality of life assessment. The whoqol group. Psychol Med. 1998;28(3):551-8.

Yao, SN, Cottraux, J, Note, I, De Mey-Guillard, C, Mollard, E, Ventureyra, V. [evaluation of post-traumatic stress disorder: Validation of a measure, the pcls]. Encephale. 2003;29(3 Pt 1):232-238. 
Figure 1: Flow-chart showing the process of victim inclusion

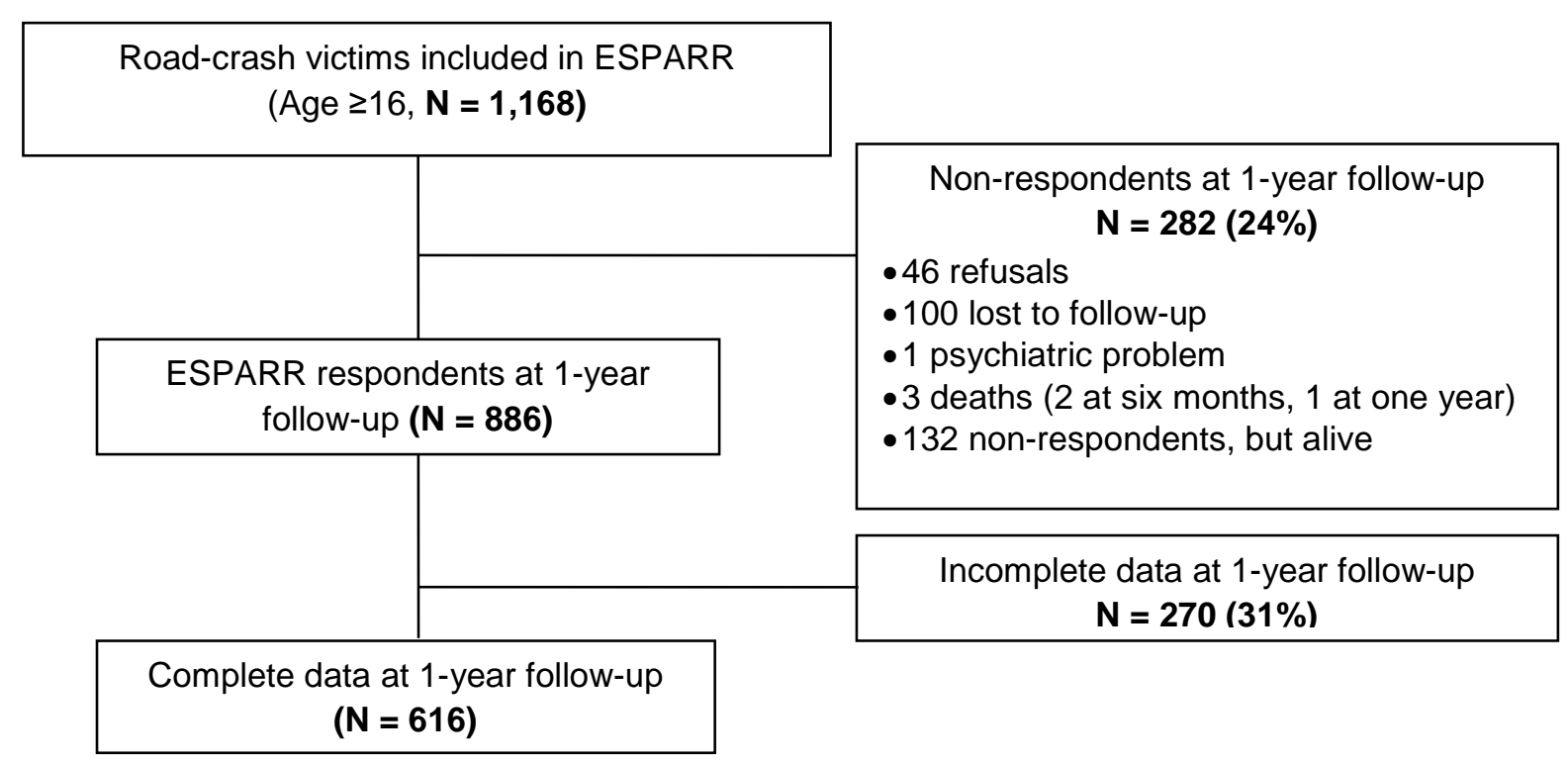


Figure 2: Mean WHOQol-Bref scores in the five outcome groups

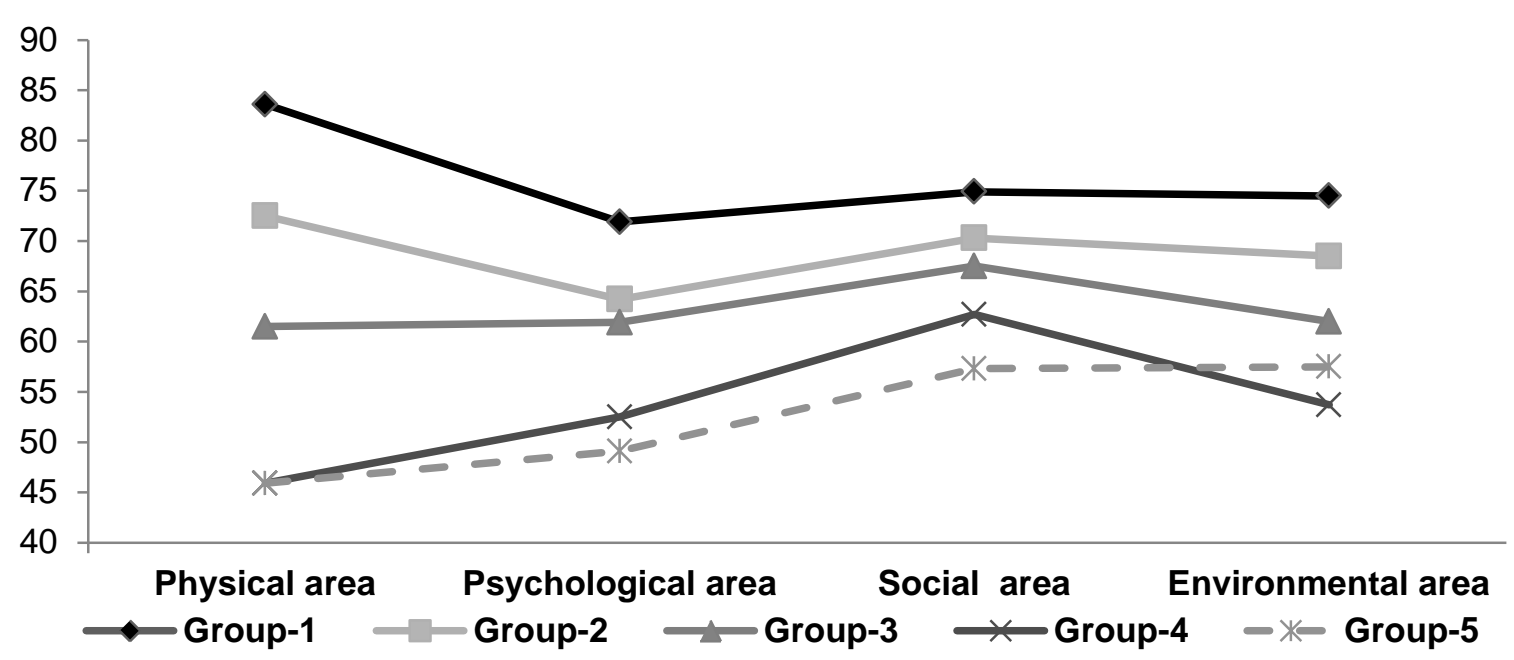


Table 1: Comparison of sociodemographic and lesion characteristics at inclusion in the 5 outcome groups [n (col\%)]

\begin{tabular}{|c|c|c|c|c|c|c|c|}
\hline Group & Group 1 & Group 2 & Group 3 & Group 4 & Group 5 & Total & p value \\
\hline Victim characteristics & $\mathrm{n}=206$ & $\mathrm{n}=168$ & $\mathrm{n}=159$ & $\mathrm{n}=43$ & $\mathrm{n}=40$ & $\mathrm{n}=616$ & \\
\hline \multirow[t]{5}{*}{ Age at crash (years) } & & & & & & & $n s$ \\
\hline & 75 (36.4) & $51(30.4)$ & 49 (30.8) & $6(14.0)$ & $15(37.5)$ & $\begin{array}{l}196 \text { (31.8) } \\
\quad{ }^{3}\end{array}$ & \\
\hline & 74 (35.9) & 66 (39.3) & $70(44.0)$ & 21 (48.8) & $16(40.0)$ & 247 (40.1) & \\
\hline & 38 (18.5) & $40(23.8)$ & 30 (18.9) & $11(25.6)$ & $6(15.0)$ & ${ }^{125}$ (20.3) & \\
\hline & 19 (9.2) & $11(6.6)$ & $10(6.3)$ & $5(11.6)$ & $3(7.5)$ & 48 (7.8) & \\
\hline Male & $116(56.3)$ & 96 (57.1) & $106(66.7)$ & $30(69.8)$ & $22(55.0)$ & 370 & $n s$ \\
\hline \multirow{5}{*}{ Separated, divorced, widowed } & & & & & & & $<0.01$ \\
\hline & $98(47.6)$ & 67 (39.9) & 59 (37.1) & $12(27.9)$ & $24(60.0)$ & 260 & \\
\hline & $83(40.3)$ & 77 (45.8) & 81 (50.9) & 15 (34.9) & 15 (37.5) & 271 (44.0) & \\
\hline & 25 (12.1) & $24(14.3)$ & 19 (12.0) & $16(37.2)$ & $1(2.5)$ & 85 (13.8) & \\
\hline & & & & & & & $<0.01$ \\
\hline A & 39 (18.9) & 19 (11.3) & 25 (15.7) & $6(14.0)$ & 9 (22.5) & 98 (15.9) & \\
\hline$B$ & $42(20.4)$ & $21(12.5)$ & 21 (13.2) & $3(7.0)$ & $6(15.0)$ & 93 (15.1) & \\
\hline C & 10 (4.9) & $10(6.0)$ & $8(5.0)$ & $4(9.3)$ & $1(2.5)$ & 33 (5.4) & \\
\hline D & 5 (2.4) & $4(2.4)$ & $5(3.1)$ & $2(4.7)$ & $0(0.0)$ & 16 (2.6) & \\
\hline$E$ & 93 (45.1) & $97(57.7)$ & $80(50.3)$ & $16(37.2)$ & $18(45.0)$ & 304 & \\
\hline $\mathrm{F}$ & 17 (8.3) & 17 (10.1) & $20(12.6)$ & $12(27.9)$ & $6(\mathbf{1 5 . 0 )}$ & 72 (11.7) & \\
\hline Relative injured in accident & $33(16.0)$ & 33 (19.6) & $22(13.8)$ & 10 (23.3) & $14(35.0)$ & 112 (18.2) & 0.02 \\
\hline Responsibility for accident & 81 (39.3) & $49(29.2)$ & $52(32.7)$ & 12 (27.9) & $8(20.0)$ & $202(32.8)$ & ns \\
\hline
\end{tabular}


Pedestrian, inline skate, push scooter 29 (14.1)

\begin{tabular}{|c|c|c|c|c|c|c|}
\hline Pedestrian, inline skate, push scooter & 29 (14.1) & $24(14.3)$ & $28(17.6)$ & 9 (20.9) & $6(15.0)$ & $\begin{array}{l}96 \\
\quad(15.6)\end{array}$ \\
\hline Bicycle & 27 (13.1) & 24 (14.3) & 12 (7.6) & $6(14.0)$ & $6(15.0)$ & $\begin{array}{l}75 \text { (12.2) } \\
\quad{ }^{2}\end{array}$ \\
\hline Two-wheel motor vehicle, quad bike & $55(26.7)$ & 50 (29.8) & $63(39.6)$ & 7 (16.3) & 7 (17.5) & ${ }^{182}$ \\
\hline Four-wheeled vehicle & 95 (46.1) & 70 (41.7) & 56 (35.2) & 21 (48.8) & $21(52.5)$ & 263 (42.7) \\
\hline
\end{tabular}

New Injury Severity Score (NISS)

\begin{tabular}{|c|c|c|c|c|c|c|c|c|}
\hline & \multicolumn{2}{|c|}{ NISS [0 to 8] 151 (73.3) } & 92 (54.8) & $58(36.5)$ & 9 (20.9) & $11(27.5)$ & \multirow{2}{*}{$\begin{array}{l}321 \\
132 \\
\quad(52.1) \\
\quad(21.4)\end{array}$} & \\
\hline & NISS [9 to 15$]$ & 34 (16.5) & $40(23.8)$ & $40(25.2)$ & $10(23.3)$ & $8(20.0)$ & & \\
\hline & NISS $\geq 16$ & $21(\mathbf{1 0 . 2 )}$ & $36(21.4)$ & 61 (38.4) & 24 (55.8) & $21(52.5)$ & 163 (26.5) & \\
\hline Head injury & & 85 (41.3) & 76 (45.2) & 63 (39.6) & 17 (39.5) & $40(100.0)$ & 281 (45.6) & - \\
\hline Face injury & & $46(22.3)$ & 36 (21.4) & $33(20.8)$ & 16 (37.2) & $18(45.0)$ & 149 (24.2) & ns \\
\hline Whiplash injury & & $57(27.7)$ & $47(28.0)$ & 30 (18.9) & 7 (16.3) & $10(25.0)$ & ${ }^{151}$ (24.5) & ns \\
\hline Thorax injury & & 12 (5.8) & 20 (11.9) & $27(17.0)$ & $13(30.2)$ & 9 (22.5) & ${ }^{81}$ (13.1) & $<0.01$ \\
\hline Abdomen injury & & 14 (6.8) & $24(14.3)$ & 20 (12.6) & 7 (16.3) & 9 (22.5) & ${ }^{74}$ (12.0) & $n s$ \\
\hline Spine without whiplash injury & & $15(7.3)$ & 22 (13.1) & 34 (21.4) & 9 (20.9) & $10(25.0)$ & $\begin{array}{l}90 \\
\quad(14.6)\end{array}$ & $<0.01$ \\
\hline Upper-limb injury & & $72(35.0)$ & 73 (43.5) & 66 (41.5) & 18 (41.9) & 21 (52.5) & $\begin{array}{l}250 \\
\quad(40.6)\end{array}$ & $n s$ \\
\hline Lower-limb injury & & $82(39.8)$ & 78 (46.4) & 107 (67.3) & 32 (74.4) & 19 (47.5) & $\begin{array}{l}318 \\
\quad(51.6)\end{array}$ & 0.02 \\
\hline
\end{tabular}

ns: non-significant; * A : subjects considered socially integrated; B: the youngest group, living in their family; $C$ : the oldest group, essentially men, non-salaried working group, i.e. farmers, or shopkeepers or craftsmen; $D$ : a young group with more females, more single-parent families, living in periurban areas; $E$ : group with financial difficulties but stable family, more frequently living in poor socioeconomic area, working as blue-collars or employees; $F$ : considered as the most social exposed group, many with no complementary social insurance, no job or an unstable job, more frequently living in poor social areas, with financial and affective problems the year before the accident. 
Table 2: Global health-related quality of life and satisfaction, WHOQOI-Bref scores by group

\begin{tabular}{|c|c|c|c|c|c|c|c|c|c|c|c|c|}
\hline \multirow[b]{2}{*}{ WHOQol-Bref } & \multicolumn{2}{|c|}{ Group 1} & \multicolumn{2}{|c|}{ Group 2} & \multicolumn{2}{|c|}{ Group 3} & \multicolumn{2}{|c|}{ Group 4} & \multicolumn{2}{|l|}{ Group 5} & \multicolumn{2}{|c|}{ Total } \\
\hline & $n=206$ & (col\%) & $n=168$ & (col\%) & $n=159$ & $(\mathrm{col} \%)$ & $n=43$ & (col\%) & $n=40$ & $(\mathrm{col} \%)$ & $n=616$ & (col\%) \\
\hline \multicolumn{13}{|l|}{ How would you rate your quality of life? } \\
\hline Very poor/poor & 3 & (1.5) & 4 & $(2.4)$ & 19 & $(12.2)$ & 16 & $(38.1)$ & 15 & $(37.5)$ & 57 & $(9.3)$ \\
\hline Neither poor nor good & 34 & $(16.5)$ & 50 & $(29.8)$ & 63 & $(40.4)$ & 16 & $(38.1)$ & 13 & $(32.5)$ & 176 & $(28.8)$ \\
\hline Good/very good & 169 & $(82.0)$ & 114 & $(67.9)$ & 74 & $(47.4)$ & 10 & $(23.8)$ & 12 & $(30.0)$ & 379 & $(61.9)$ \\
\hline \multicolumn{13}{|l|}{ How satisfied are you with your health? } \\
\hline Very dissatisfied/ dissatisfied & 5 & $(2.4)$ & 33 & $(19.6)$ & 67 & $(43.0)$ & 29 & (96.1) & 30 & $(75.0)$ & 164 & $(26.8)$ \\
\hline Neither satisfied nor dissatisfied & 31 & (15.1) & 53 & $(31.6)$ & 43 & $(27.6)$ & 5 & (11.9) & 6 & $(15.0)$ & 138 & $(22.6)$ \\
\hline Satisfied/very satisfied & 170 & $(82.5)$ & 82 & $(48.8)$ & 46 & $(29.5)$ & 8 & (19.1) & 4 & $(10.0)$ & 310 & $(50.7)$ \\
\hline WHOQol-Bref scores & $M(S D)$ & range & $\mathrm{M}(S D)$ & range & $M(S D)$ & range & $M(S D)$ & range & $M(S D)$ & range & $M(S D)$ & range \\
\hline Physical area & 83.6(11.5) & 41.7-100 & 72.5(13.9) & $25.0-100$ & $61.5(20.0)$ & 7.1-100 & $45.9(22.1)$ & $0-85.7$ & $45.9(22.0)$ & $0-92.9$ & $69.9(20.5)$ & $0-100$ \\
\hline Psychological area & $71.9(13.4)$ & 29.3-100 & 64.2(15.7) & $16.7-100$ & $61.9(17.8)$ & $0-91.7$ & $52.5(23.0)$ & 4.2-91.7 & 49.1(17.5) & $0-79.2$ & 64.4(17.6) & $0-100$ \\
\hline Social area & $74.9(15.4)$ & $8.3-100$ & 70.3(17.6) & $0.0-100$ & 67.5(17.0) & 8.3-100 & $62.7(26.5)$ & $0-100$ & $57.3(27.6)$ & $0-100$ & 69.8(18.9) & $0-100$ \\
\hline Environmental area & 74.5(13.7) & $31.3-100$ & $68.5(14.5)$ & $31.3-100$ & $62.0(17.8)$ & $9.4-100$ & $53.7(19.2)$ & $3.1-87.5$ & $57.5(17.1)$ & $\begin{array}{r}25.0- \\
90.6\end{array}$ & $67.1(17.0)$ & $\begin{array}{c}3.1- \\
100\end{array}$ \\
\hline
\end{tabular}

M: Mean, SD: standard deviation 


\begin{tabular}{|c|c|c|c|c|c|c|}
\hline \multirow[b]{3}{*}{ Age at accident (yrs) } & & $\begin{array}{l}\text { Group } 2 \\
(n=168)\end{array}$ & $\begin{array}{l}\text { Group } 3 \\
(n=159)\end{array}$ & $\begin{array}{c}\text { Group } 4 \\
(n=43)\end{array}$ & $\begin{array}{c}\text { Group } 5 \\
(n=40)\end{array}$ & \multirow[t]{2}{*}{$p$ value* } \\
\hline & & OR $\quad(95 \% C l)$ & OR $(95 \% \mathrm{Cl})$ & $(95 \% \mathrm{Cl})$ & OR $\quad(95 \% C l)$ & \\
\hline & & & & & & 0.01 \\
\hline & $16-24$ & 1 & 1 & 1 & 1 & \\
\hline & $25-44$ & $1.3(0.7-2.5)$ & $1.3(0.6-2.7)$ & $9.4(2.8-31.6)$ & $1.1(0.3-3.7)$ & \\
\hline & $45-64$ & $1.3(0.6-2.9)$ & $0.9(0.3-2.2)$ & $6.3(\mathbf{1 . 4 - 2 8 . 0 )}$ & $0.4(0.1-2.3)$ & \\
\hline & $\geq 65$ & $0.9(0.3-2.7)$ & $0.4(0.1-1.7)$ & $24.9(2.8-221.3)$ & $0.6(0.1-4.3)$ & \\
\hline Gender & & & & & & ns \\
\hline & Male vs Female & $0.7(0.4-1.2)$ & $0.8(0.5-1.5)$ & $0.5(0.1-1.6)$ & $0.8(0.3-2.5)$ & \\
\hline Level of socioeconomic fragility ** & & & & & & $<0.01$ \\
\hline & $A$ & 1 & 1 & 1 & 1 & \\
\hline & $\mathrm{B}$ & $1.0(0.4-2.8)$ & $0.4(0.1-1.3)$ & $0.8(0.1-5.0)$ & $0.4(0.1-2.1)$ & \\
\hline & $\mathrm{C}$ & $2.1(0.5-8.6)$ & $1.3(0.3-4.9)$ & $2.7(0.4-16.9)$ & $1.7(0.1-21.2)$ & \\
\hline & $\mathrm{D}$ & $2.2(0.4-11.6)$ & $1.4(0.2-8.8)$ & 11.6 (1.2-109.9) & - & \\
\hline & $E$ & $2.1(1.0-4.6)$ & $0.8(0.4-1.8)$ & $5.4(1.2-24.3)$ & $0.6(0.2-2.4)$ & \\
\hline & $\mathrm{F}$ & $2.7(0.9-7.8)$ & $1.7(0.6-5.1)$ & 35.8 (7.1-181.5) & $1.5(0.3-8.0)$ & \\
\hline Relative involved in accident & & & & & & 0.02 \\
\hline New Injury Severity Score (NISS) & Yes vs No & $1.7(0.9-3.4)$ & $1.5(0.7-3.2)$ & $3.2(0.9-11.6)$ & 5.7 (1.9-17.0) & $<0.01$ \\
\hline & NISS $\geq 9$ vs NISS $0-8$ & 2.8 (1.4-5.5) & $3.2(1.6-6.5)$ & $7.2(2.0-25.6)$ & 10.4 (3.0-35.8) & \\
\hline Non-whiplash spinal lesion & & & & & & 0.02 \\
\hline & Yes vs No & $2.0(0.9-4.6)$ & 4.3 (1.8-10.6) & $2.6(0.6-11.1)$ & $1.8(0.4-7.8)$ & \\
\hline Lower-limb lesion & Yes vs No & $1.3(0.8-2.2)$ & $2.4(1.3-4.4)$ & $2.8(0.9-8.8)$ & $1.2(0.4-3.3)$ & 0.04 \\
\hline
\end{tabular}

OR: odds ratio for falling in a given consequence group; Cl: Confidence interval; ns: non-significant; *multivariate analysis, weighted multinomial logistic regression model, reference group = group $1 ;{ }^{* *} A$ : subjects considered socially integrated; $B$ : the youngest group, living in their family; $C$ : the oldest group, essentially men, non-salaried working group, i.e. farmers, shopkeepers or craftsmen; $D$ : a young group with more females, more single-parent families, living in periurban areas; $E$ : group with financial difficulties but stable family, more frequently living in poor socioeconomic areas, working as blue-collars or employees; $F$ : considered the most social exposed group, many with no complementary social insurance, no job or an unstable job, more frequently living in poor social areas, with financial and affective problems the year before the accident. 


\section{APPENDIX}

General health perception victims were considered as having good health status at 1 year if they described their medical condition as fully recovered, they had good physical consolidation, and their morale was no longer affected by the crash. In contrast, if victims had at least 1 negative self-assessment on these items, they were considered as having not recovered good health status.

Sequelae Victims described the sequelae they suffered at 1 year (pain, non-union, sensory sequelae, etc.). Responses were then validated and coded by the team physician.

Disruption of recreational Victims reported whether the crash had disrupted their recreational activities (sport, music, holidays, travel, activities etc.).

Disruption of working life Victims reported whether the crash had disrupted their working life (job, promotion, projects, etc.).

Medication Victims reported any medical treatment at 1 year in relation with the crash (painkillers, neurologic treatment,

\begin{tabular}{l}
$\begin{array}{l}\text { Psychological outcome } \\
\text { measures }\end{array}$ \\
\hline
\end{tabular}

Increased psychiatric treatment Victims reported any increase in the dose of psychiatric treatment between the time before the accident and

Post-traumatic stress disorder PTSD is a severe anxiety condition that can arise after a traumatic event. It was assessed using the Post(PTSD) traumatic Checklist Scale (PCLS) (Weathers et al. 1993), translated into French and validated by Yao and Ventureyra (Yao et al. 2003). The PCLS comprises 17 items relating to the 3 dimensions of the disorder: reexperiencing, avoidance and hyperarousal.

Post-concussion syndrome Victims were classified on the criteria set out by the International Statistical Classification of Diseases and Related Health Problems (WHO-icd10)(WHO) for consequences of head injuries sustained in a crash. The symptoms used for classification were: headache, dizziness, fatigue, irritability, sleep disturbance, reduced concentration, reduced memory, and sensitivity to noise and light.

Social outcome measures

Consequences for the family Victims reported whether the crash had affected the daily life of their family (work duration, daily burden, etc.). Emotional life upset Victims reported whether they thought the crash had upset their emotional life (family harmony, sexual life, friends, etc.).

\section{Environmenta} outcome

Victims reported whether, since the accident, they had not returned home or needed changes made to their home or changed houses for health reasons, or were in a daytime activity center or occupational center.

Change in projects Victims reported whether they had had to change their projects since the crash (baby, marriage, real estate, etc.).

Financial problems Victims reported whether the crash still affected their finances, notably in relation to problems of work. 
Table A2: Descriptive outcome information on the 5 outcome groups at 1 year

\begin{tabular}{|c|c|c|c|c|c|c|}
\hline Group & Group 1 & Group 2 & Group 3 & Group 4 & Group 5 & Total \\
\hline Outcome* & $\mathrm{n}=206$ (col\%) & $\mathrm{n}=168(\mathrm{col} \%)$ & $\mathrm{n}=159(\mathrm{col} \%)$ & $\mathrm{n}=43$ (col\%) & $\mathrm{n}=40 \operatorname{col}(\%)$ & $\mathrm{n}=616(\mathrm{col} \%)$ \\
\hline \multicolumn{7}{|l|}{ Physical outcome } \\
\hline Health not fully recovered & $54(26.2)$ & $151(89.9)$ & $157(98.7)$ & $43(100)$ & 39 (97.5) & 444 (72.1) \\
\hline Persistent sequelae & 47 (22.8) & $131(78.0)$ & $152(95.6)$ & 41 (95.3) & $38(95.0)$ & 409 (66.4) \\
\hline Disruption of recreational activities & 24 (11.7) & 76 (45.2) & $141(88.7)$ & 41 (95.3) & $33(82.5)$ & 315 (51.1) \\
\hline Disruption of working life & 29 (14.1) & $58(34.5)$ & $110(69.2)$ & 32 (74.4) & 29 (72.5) & 258 (41.9) \\
\hline On medical treatment & $4(1.9)$ & 78 (46.4) & $82(51.6)$ & 32 (74.4) & 31 (77.5) & $227(36.9)$ \\
\hline \multicolumn{7}{|l|}{ Psychological outcome } \\
\hline Increased psychiatric treatment & $0(0)$ & $38(22.6)$ & 45 (28.3) & $18(41.9)$ & $20(50.0)$ & 121 (19.6) \\
\hline Post-traumatic stress disorder & 4 (1.9) & $21(12.5)$ & $45(28.3)$ & 15 (34.9) & $30(75.0)$ & 115 (18.7) \\
\hline Post-concussion syndrome & $0(0)$ & $0(0)$ & $0(0)$ & $0(0)$ & $40(100)$ & $40(6.5)$ \\
\hline \multicolumn{7}{|l|}{ Social outcome } \\
\hline Consequences for the family & 23 (11.2) & 20 (11.9) & 121 (76.1) & $33(76.7)$ & $28(70.0)$ & $225(36.5)$ \\
\hline Emotional life upset & $23(11.2)$ & $13(7.7)$ & 102 (64.2) & 25 (58.1) & $27(67.5)$ & $190(30.8)$ \\
\hline \multicolumn{7}{|l|}{ Environmental outcome } \\
\hline Change in accommodation & $5(2.43)$ & $0(0)$ & $0(0)$ & $43(100)$ & $12(\mathbf{3 0 . 0})$ & $60(9.7)$ \\
\hline Change in projects & 27 (13.1) & $14(8.3)$ & 93 (58.5) & $33(76.7)$ & 29 (72.5) & 196 (31.8) \\
\hline Financial problems & 30 (14.6) & 56 (33.3) & 85 (53.5) & 31 (72.1) & $23(57.5)$ & 225 (36.5) \\
\hline
\end{tabular}


Table A3: Descriptive Injury Impairment Scale indicators in the 5 outcome groups at 1 year

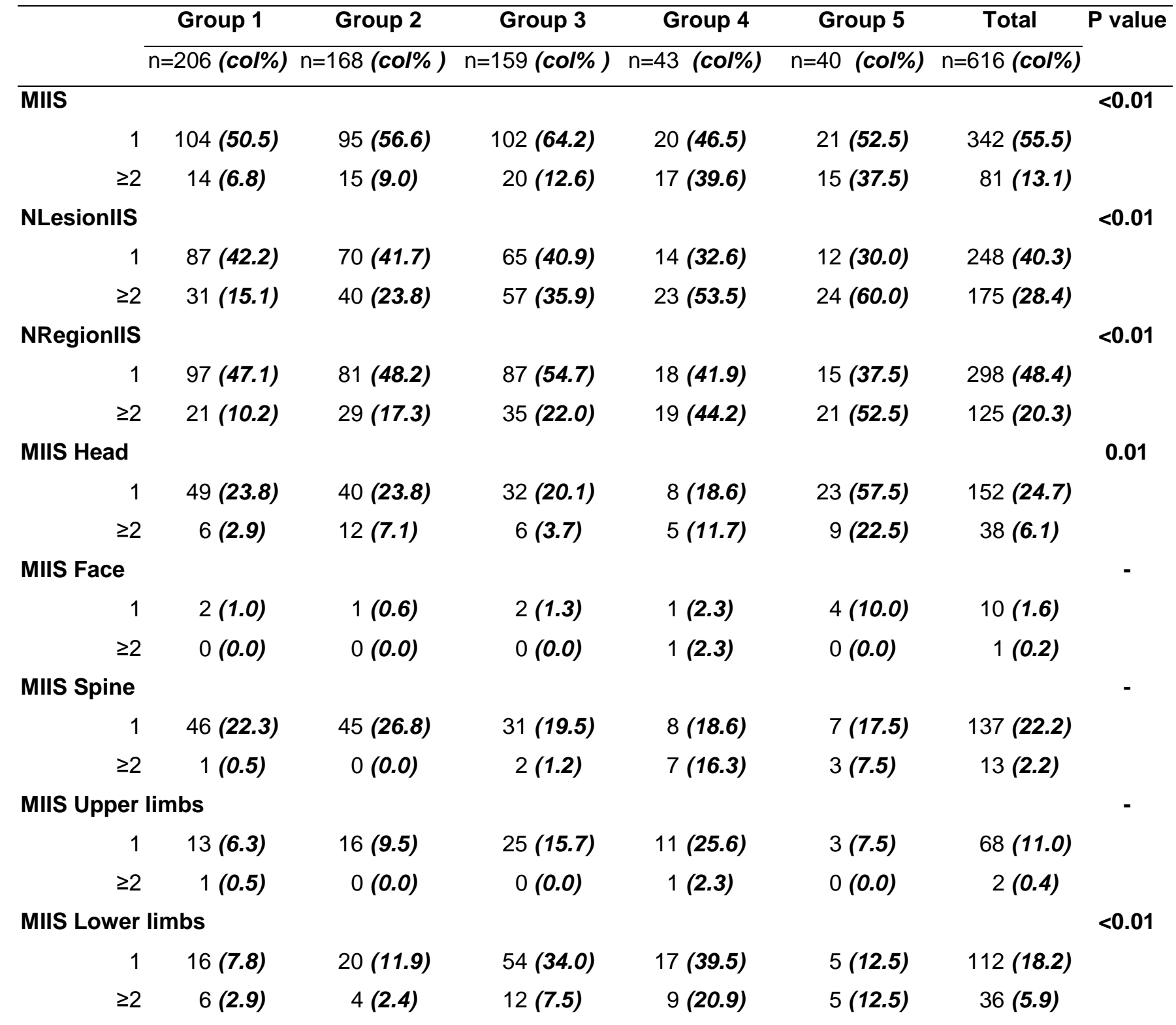

ns: non-significant; MIIS : Maximum Injury Impairment Scale ; NLesionIIS : number of lesions giving IIS>0; NRegionIIS: number of the body regions having at least one IIS> 0. 